\title{
Systematic Reviews of Prevalence and Associated Factors of Hypertension in Ethiopia: Finding the Evidence
}

\author{
Mulugeta Molla \\ Mekelle University, College of health Sciences, Department of Nursing, Mekelle, Ethiopia
}

Email address:

mulerwarso@gmail.com

To cite this article:

Mulugeta Molla. Systematic Reviews of Prevalence and Associated Factors of Hypertension in Ethiopia: Finding the Evidence. Science Journal of Public Health. Vol. 3, No. 4, 2015, pp. 514-519. doi: 10.11648/j.sjph.20150304.19

\begin{abstract}
Background: Hypertension is one of the leading causes of global burden of disease. This paper is intended to provide compressive and up to date evidence on the prevalence and investigate the associated factors of Hypertension in Ethiopia from January, 2000 to April, 2015. Methods: A quantitative epidemiological systematic literature review was conducted by searching different published articles in different data bases which is written in English including MEDLINE, PubMed, CINAHL, Google scholar, Cochrane and grey literatures. The search was restricted to population based studies on hypertension in Ethiopia published between January 2000 and April 2015. All data were extracted independently by a single reviewer using a standardized protocol and data collection form. Nine publications met the inclusion criteria. The total pooled data were nine surveys involving over 13,327 participants. Results: The reported rate of hypertension is varied widely, with the highest rate of $31.5 \%$ in male and the lowest rate of $0.8 \%$ in female, partly because of the differences in participants mean ages, source population and study settings. This review found a high prevalence of hypertension in urban residents and different associated factors including overweight, family history of hypertension, age, sex, sleeping for less than 5 hours, Oral contraceptive use, alcohol intake, physical inactivity, eating vegetable three or fewer days per week, salt use, obesity, higher education and vigorous recreational activities were identified. Conclusion and recommendation: Hypertension was considerably prevalent in Ethiopia. Health promotion strategy tailored to the education on modifiable risk factors and establishment of blood pressure screening in primary health care context would be of immense value both in urban and rural areas. This study was highlighting the need for implementation of timely and appropriate strategies for prevention and control of hypertension. Upcoming well-powered studies, using the standardized research design and covering more regions of the country are recommended. Further Meta-analysis study is also recommended.
\end{abstract}

Keywords: Prevalence, Associated Factors, Hypertension, Best Evidence, Systematic Review, Ethiopia

\section{Background}

Hypertension is one of the leading causes of global burden of disease. In the year 2000, analysis of the global burden of hypertension indicated that over $25 \%$ of world's adult population had hypertension and the proportion is estimated to rise to $29 \%$ by 2025 (1).

The global prevalence of raised blood pressure (defined as systolic and/or diastolic blood pressure $\geq 140 / 90 \mathrm{mmHg}$ ) in adults aged 18 years and over was around $22 \%$ in 2014 (2, 3 ).Across the WHO regions, the prevalence of raised blood pressure was highest in Africa, at 30\% for all adults combined. The lowest prevalence of raised blood pressure was in the Region of the Americas, at $18 \%$. In those regions, Men have slightly higher prevalence of raised blood pressure than women. (2)

Globally CVD accounts for approximately 17 million deaths a year, nearly one third of the total. (4) Of these, complications of hypertension account for 9.4 million deaths worldwide every year. (5). Hypertension is responsible for at least $45 \%$ of deaths due to heart disease and $51 \%$ of deaths due to stroke. (4)

Globally raising blood pressure is one of the leading risk factor for mortality and is estimated to have caused 9.4 million deaths and $7 \%$ of deaths burden- as measured in disability-adjusted life years - in 2010. The leading global risks for mortality in the world are high blood pressure (responsible for $13 \%$ of deaths globally), tobacco use (9\%), high blood glucose (6\%), Physical inactivity $(6 \%)$, and overweight and obesity (5\%). These risks are responsible for raising the risk of chronic diseases such as heart disease, 
diabetes and cancers. They affect countries across all income groups: High, middle and low. $(5,6)$

Raised blood pressure is a major cardiovascular risk factor. If left uncontrolled, hypertension causes stroke, myocardial infarction, cardiac failure, dementia, renal failure and blindness, causing human suffering and imposing severe financial and service burdens on health systems $(7,8)$.

Many factors contribute to the high prevalence rates of hypertension including eating food containing too much salt and fat; not eating enough fruits and vegetables; overweight and obesity; harmful use of alcohol; physical inactivity; ageing; genetic factors; psychological stress; socioeconomic determinants and inadequate access to health care. (2)

The increasing prevalence of hypertension is attributed to population growth, aging and behavioral risk factors, such as unhealthy diet, harmful use of alcohol, lack of physical activity, excess weight and exposure to persistent stress. The adverse health consequences of hypertension are compounded because many people affected also have other health risk factors that increase the odds of heart attack, stroke and kidney failure. These risk factors include tobacco use, obesity, high cholesterol and diabetes mellitus. Tobacco use increases the risk of complications among those with hypertension. (9)

According to W.H.O global status report, there is an agreed set of very cost-effective - and globally applicable-NCD interventions for attaining all nine targets by 2025 . Among all the targets, the $6^{\text {th }}$ global target is $25 \%$ relative reduction in the prevalence of raised blood pressure or contain the prevalence of raised blood pressure, according to national circumstances.(2)

According to W.H.O the crude adjusted estimate of raised blood pressure for those aged $18^{+}$years in Ethiopia were males 24 with 95\% CI [16.9-31.7] and Female 95\% CI [17.3-31.3]. (2)

Over the period 2011-2025 the cumulative lost output in low and middle-income countries associated with NCDs is projected to be US\$ 7.28 trillion (10). The annual loss of approximately US\$ 500 billion due to major NCDs amounts to approximately $4 \%$ of gross domestic product for low and middle-income countries. Cardiovascular disease including hypertension accounts for nearly half of the cost. (11).

The prevention and control of hypertension has not received due attention by many developing countries. Hypertension is one of the most modifiable risk factors for cardiovascular diseases. However, awareness about treatment and control of hypertension is extremely low among developing nations including Ethiopia. In these countries health care resources are overwhelmed by other priorities including HIV/AIDS, tuberculosis and malaria. (12)

Ethiopia is an ancient country, situated in the Horn of Africa. It is one of the cradles of mankind, for instance, "Dinknesh" or "Lucy" and Ardi was discovered in Hadar in 1974 and 1994 respectively. "Lucy" was dates back 3.5 million years and Ardi dates back 4.5 million years. Throughout its long history Ethiopia has been a melting pot of diverse customs and cultures. (13)
Ethiopia was one of few African countries that maintained its independence, founding members of UN, OAU, and seat of AU. At present Ethiopia is administratively structured in to nine regional states and two city administrations. (13)

Even though there are some pocket studies across different regions, to my knowledge reliable information's about the prevalence and associated factors of hypertension results in different regions of Ethiopia have not been pooled and done together. These kinds of evidences are important for understanding the magnitude of the problem, the risk groups and it will have a paramount effect in effective preventive and control strategies for policy makers, researchers, educators, and all other concerned bodies.So, this initiated me to conduct a systematic review in this area.

The objective of the present study was to synthesize the current prevalence and investigate the associated factors for hypertension in Ethiopia; based on the studies published between January, 2000 and April, 2015.

\section{Methods}

The reporting of this review adhered to the preferred reporting items for systematic reviews and meta-analysis (PRISMA) statements. (14)

\subsection{Study Search}

A systematic review of all papers published on hypertension in Ethiopia between January, 2000 and April, 2015, which are available on PubMed, EMBASE, Google Scholar and Cochrane were searched. The articles were searched for providing data from Ethiopia on non communicable diseases, cardiovascular diseases, hypertension, prevalence, incidence, causes, determinants, associated factors and cross sectional studies. Grey literature, from sources including the websites of world health organization and National and international hypertension organization were reviewed. The researcher manually searched the references of selected studies for any additional studies that were not captured by the electronic search using references cited in original study articles and reviews.

\subsection{Study Selection}

The eligibility criteria for this paper were papers which had clear objectives and methodology, cross sectional studies, Englishlanguage, and fullarticle, carried out in Ethiopia, and published and unpublished articles from January, 2000 to April, 2015. Published studies, which reported the prevalence of hypertension and were conducted in representative population samples, were included in the review. When information needed to consider eligibility was missing, the study was excluded.

\subsection{Study Population}

Males and females aged $\geq 15$ years, residing in Ethiopia were participated in this research. 


\subsection{Study Outcomes}

The primary outcome of this review was overall prevalence of hypertension in Ethiopia and the secondary outcome was risk factors associated with HPT.

The determination of HPT was made by SBP/DBP $\geq$ 140/90 mm Hg measured twice or the self-reported HPT and on antihypertensive medication as described by the 7th Joint National Committee (JNC7). (3)

\subsection{Study Design}

Community and institution based cross-sectional studies that were carried out in Ethiopia including more than 400 participants and reported prevalence of HPT were included. Studies were excluded if they did not provide the prevalence of HPT and failed to follow the JNC7 standards for self reported HPT (i.e., self-reported HPT without BP measurement and without taking antihypertensive medication).

\subsection{Data Extraction}

All data were extracted independently by a single reviewer using a standardized protocol and data collection form. Uncertainties were resolved by discussion with one colleague and during disagreement the final decision was made based on the opinion of senior experts and majority decision was taken.

Data on year of publication and survey, region of study, age of participants, sampling methods, study design, response rate, sample size, and measurement of blood pressure, definition(s) used for hypertension, number of BP measurement and type of measuring device used were extracted. Prevalence of hypertension and associated factors were also obtained.

The author described the population used for the standardization of hypertension prevalence where this information was available. Where information was available, the prevalence was obtained by age, gender, socio-economic status, and rural-urban residence. Multiple papers from a study were included if these were found and consistency of results checked for the same study.

\section{Result}

\subsection{Study Selection}

In the initial search 80 articles were identified and 9 studies were deemed eligible. Figure 1 shows the PRISMA flow chart of the selection of studies. Those nine studies $(n=13,327)$ were selected for this review.

Four of them were done in 2013, two of them were carried out in 2012 and the rest were done in 2009/2010.
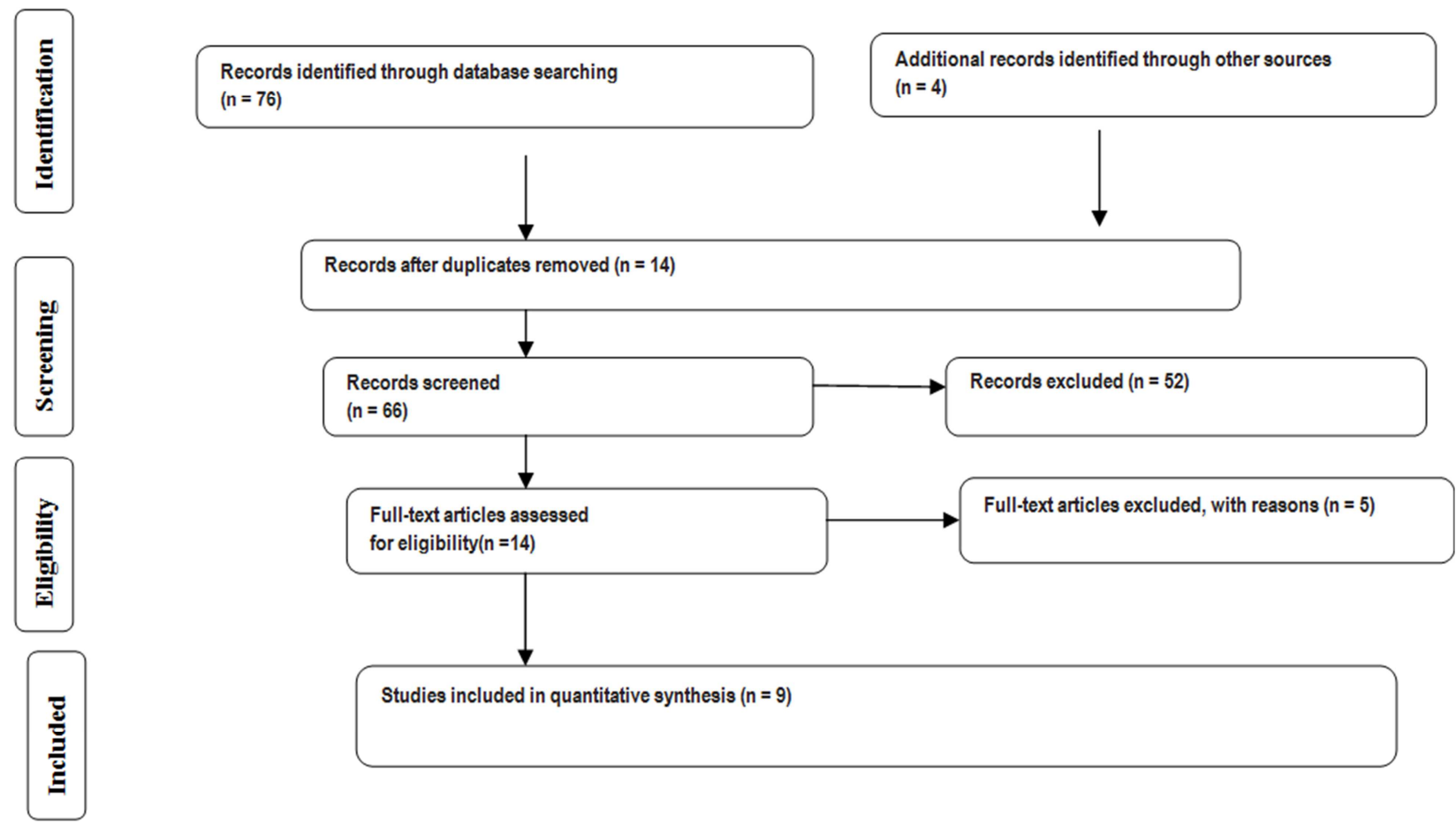

Figure 1. PRISMA flowchart of the selection of studies. Adapted from Moher et al. (14).

\subsection{Characteristics of the Studies}

All selected studies were cross sectional design (Table 1). The studies included participants, ranging from 422(15) to 4469 (16). The largest study was carried out in Oromia region in Gilgel Gibe field research center, South West Ethiopia.

All included studies were done with different standardized age. Three numbers of studies were done with participant age $\geq 15$ years $(15,17)$ and three other studies were carried out with age $\geq 18(18,19,20)$ years. The rest were done with participant's age of $\geq 25(21), \geq 31(22)$ and $\geq 35(23)$ years.

Among all, seven studies were conducted in urban areas $(15,17,18,20-23)$. The rest two studies were both urban and rural settings $(16,19)$. Among nine included studies, all 
studies were diagnosis of HPT by JNC7 criteria.

\subsection{Risk of Bias}

Among included studies all are random sampling techniques. The maximum and minimum response rate was about $99.7 \%$ (20) and 91\% (for the largest scale survey)(16) respectively, while in three studies the non response rate was absolutely zero $(17,18,19)$.

\subsection{Prevalence of Hypertension}

The prevalence of hypertension in Ethiopia among different regions is presented in Table 1. Even though some regional studies have been conducted in different parts of Ethiopia, there is no national studies have been performed yet. The reported rate of hypertension is varied widely, with the highest rate of $31.5 \%$ in male $(21)$ and the lowest rate of $0.8 \%$ in female (22).But the prevalence in most of the studies was between $20 \%$ and $30 \%$.

Although there are a few studies conducted in rural setting the prevalence of hypertension in urban setting is higher than the rural counter parts. In five studies the prevalence of hypertension in male is higher than in female $(17,18,19,21$, 22). Among all regions the highest prevalence is reported in the capital city of Ethiopia, Addis Ababa and the prevalence was $31.5 \%$ in male and $28.9 \%$ in female (21), the lowest prevalence is reported in Oromia region and the prevalence was $3.1 \%$ in male and $4.4 \%$ in female(16).

The prevalence of hypertension in age group $\geq 25(21)$ years, $\geq 31(22)$ years and $\geq 35(23)$ Years were reported in three studies and the prevalence was $31.5 \%$ in male and $28.9 \%$ in female $(21), 26.2 \%$ in male and $19.4 \%$ in female (22), $26 \%$ in male and $30.3 \%$ female respectively(23). This was also the highest reported results among all studies and done age group $\geq 151(15,17)$ years and $\geq 18(19,20)$ years old.

Table 1. Prevalence and Associated risk factors of Hypertension in cross sectional surveys in Ethiopia from January, 2000 to April, 2015.

\begin{tabular}{|c|c|c|c|c|c|c|}
\hline S. No. & $\begin{array}{l}\text { Author/year of } \\
\text { publication }\end{array}$ & Year of survey & Region & Site (Urban/rural ) & $\begin{array}{l}\text { Mean age and SD/ } \\
\text { Age in Years }\end{array}$ & $\begin{array}{l}\text { Sample size } \\
\text { (response rate) }\end{array}$ \\
\hline 1. & Akilew A. et al, ${ }^{23} / 2012$ & 2012 & Amhara & Gonder/Urban & $51.5 \pm 14.4 />35$ yrs & $679 / 97.6 \%$ \\
\hline 2. & Feyie B. et al, ${ }^{15} / 2014$ & 2011 & Oromia & Bedele/Urban & $29.6 \pm 15.5 />15 \mathrm{yrs}$ & $422 / 93.8 \%$ \\
\hline 3. & Takele T. et al, ${ }^{18} / 2014$ & $2012 / 2013$ & Amhara & Gonder/Urban & $21 \pm 1.82 />18$ yrs & $610 / 0 \%$ \\
\hline 4. & Esayas K. et $\mathrm{al}^{17}$, /2013 & 2012 & Oromia & Jimma/Urban & $42.3 \pm 13.2 />15 \mathrm{yrs}$ & $734 / 0 \%$ \\
\hline 5. & Tesfa B. et $\mathrm{al}^{16}, / 2015$ & 2013 & Oromia & $\begin{array}{l}\text { Research center/Both } \\
\text { Ur\&Ru }\end{array}$ & $15-64 \mathrm{yrs} />15 \mathrm{yrs}$ & $4469 / 91 \%$ \\
\hline 6. & Fikru T. et al, ${ }^{21} / 2009$ & 2008 & Addis Ababa & Addis Ababa/Urban & $25-64 \mathrm{yrs} />25 \mathrm{yrs}$ & $4001 / 93 \%$ \\
\hline 7. & Mekoya D. et al ${ }^{19}, / 2014$ & $2010 / 2011$ & Tigray & $\begin{array}{l}\text { Mekelle\&Humera/Ur } \\
\text { \&Ruresp }\end{array}$ & I $>18 \mathrm{yrs}$ & $1183 / 0 \%$ \\
\hline 8. & Assefa B. et $\mathrm{al}^{20}{ }^{20} / 2014$ & 2013 & Tigray & Mekelle/Urban & $I>18 \mathrm{yrs}$ & $711 / 99.7 \%$ \\
\hline 9. & Tsegab P. et al, ${ }^{22} / 2014$ & 2013 & SNNP & Durame/Urban & $\overline{4} 7.4 \pm 12.2 />31 \mathrm{yrs}$ & $518 / 96.6 \%$ \\
\hline
\end{tabular}

Table 1. Continue.

\begin{tabular}{|c|c|c|c|c|c|c|c|}
\hline \multirow[b]{2}{*}{ S. No. } & \multirow{2}{*}{$\begin{array}{l}\text { Study } \\
\text { design/sampling } \\
\text { method }\end{array}$} & \multirow[b]{2}{*}{ Instrument } & \multirow{2}{*}{$\begin{array}{l}\text { No. of } \\
\text { measu/measur } \\
\text { used }\end{array}$} & \multirow{2}{*}{$\begin{array}{l}\text { Cut off point for HPT, } \\
\mathrm{mm} \mathrm{Hg}\end{array}$} & \multicolumn{2}{|c|}{ Prevalence (\%) (95\% CI) } & \multirow[b]{2}{*}{ Associated Risk factors } \\
\hline & & & & & Male & Female & \\
\hline 1. & $\mathrm{CBCS} / \mathrm{MSRS}$ & Sphy & $2 /$ mean of 2 & $\begin{array}{l}\mathrm{BP} \geq 140 / 90 \text { or Anti- } \\
\text { hypertensive Medication }\end{array}$ & $26.0 \%$ & $30.3 \%$ & $\begin{array}{l}\text { FHH,OB,SRDm,age } \geq 55 \text {, no } \\
\text { cont. walking for } 10^{\prime} / \text { day }\end{array}$ \\
\hline 2. & $\mathrm{CBCS} / \mathrm{SRS}$ & Sphy & $2 /$ mean of 2 & $\begin{array}{l}\mathrm{BP} \geq 140 / 90 \text { or Anti- } \\
\text { hypertensive Medication }\end{array}$ & $13.1 \%$ & $24.8 \%$ & Age $\geq 35$, Waist circumference \\
\hline 3. & IBCS/SRS & Sphy & $3 /$ mean of last 2 & $\begin{array}{l}\mathrm{BP} \geq 140 / 90 \text { or Anti- } \\
\text { hypertensive Medication }\end{array}$ & $6.9 \%$ & $0.8 \%$ & $\begin{array}{l}\text { Being male, OW, Sleeping } \leq \\
5 \mathrm{hr}\end{array}$ \\
\hline 4. & IBCS/SRS & Sphy & $2 /$ mean of 2 & $\begin{array}{l}\mathrm{BP} \geq 140 / 90 \text { or Anti- } \\
\text { hypertensive Medication }\end{array}$ & $15.3 \%$ & $11.7 \%$ & FHH, SRDm, OW, OCP use \\
\hline 5. & CBCS/SRS & Digital & $3 /$ mean of 3 & $\begin{array}{l}\mathrm{BP} \geq 140 / 90 \text { or Anti- } \\
\text { hypertensive Medication }\end{array}$ & $3.1 \%$ & $4.4 \%$ & $\begin{array}{l}\text { Being female, educated, ALC } \\
\text { and VRA }\end{array}$ \\
\hline 6. & CBCS/MSRS & Digital & $3 /$ mean of last 2 & $\begin{array}{l}\mathrm{BP} \geq 140 / 90 \text { or Anti- } \\
\text { hypertensive Medication }\end{array}$ & $31.5 \%$ & $28.9 \%$ & $\begin{array}{l}\text { OW, OB, Educated, WC, and } \\
\text { physical inactivity }\end{array}$ \\
\hline 7. & CBCS/MSRS & Sphy & $3 /$ mean of 3 & $\begin{array}{l}\mathrm{BP} \geq 140 / 90 \text { or Anti- } \\
\text { hypertensive Medication }\end{array}$ & $21 \%$ & $16.4 \%$ & Age, sex and OW \\
\hline 8. & CBCS/MSRS & Sphy & $3 /$ mean of last 2 & $\begin{array}{l}\mathrm{BP} \geq 140 / 90 \text { or Anti- } \\
\text { hypertensive Medication }\end{array}$ & $10.5 \%$ & $11.2 \%$ & $\begin{array}{l}\text { Age }>41 y r s \text {, educated, } O W \text { and } \\
\text { OB }\end{array}$ \\
\hline 9. & $\mathrm{CBCS} / \mathrm{SRS}$ & Sphy & $2 /$ mean of 2 & $\begin{array}{l}\mathrm{BP} \geq 140 / 90 \text { or Anti- } \\
\text { hypertensive Medication }\end{array}$ & $26.2 \%$ & $19.4 \%$ & $\begin{array}{l}\text { Age }>31 \text { yrs, FHH, OB, OW, } \\
\text { Physical inactivity, eating } \\
\text { vegetable three or fewer days } \\
\text { per week and salt use }\end{array}$ \\
\hline
\end{tabular}

$\mathrm{ALC}=\mathrm{Alcohol}, \mathrm{BP}=\mathrm{Blood}$ pressure, $\mathrm{BMI}=$ Body mass Index, $\mathrm{CBCS}=$ community based cross sectional study, Cont. $=$ continuous, $\mathrm{FHH}=\mathrm{Family}$ history of Hypertension, HPT= Hypertension, $\mathrm{Hr}=$ hour, $\mathrm{IBCS}=$ institution based cross sectional study, MSRS=Multi stage random sampling, $\mathrm{OB}=\mathrm{Obesity}(\mathrm{BMI}>30)$, $\mathrm{OCP}=$ oral combined contraceptives use, $\mathrm{OW}=$ over weight $(\mathrm{BMI}=25.0-29.9), \mathrm{SD}=\mathrm{Standard}$ deviation, $\mathrm{S}$. No. $=$ serial number, Sphy $=\mathrm{Standard}$ mercury sphygmomanometer, SRDm= Self reported Diabetes Mellitus, SRS=systematic random sampling, Ur/Ru=Urban/Rural, VRA=vigorous recreational activity, $\mathrm{WS}=$ waist circumference, Yrs=years, '=minute 


\subsection{Risk Factors of Hypertension}

From all studies six studies identified overweight as a potential risk factor for hypertension (17-22). In two studies self reported diabetes is reported as a risk factor for hypertension $(17,23)$. In other three studies family history of hypertension is identified as a risk factor for hypertension. $(17,22,23)$. Age $(15,19,20,22,23)$ and sex $(16,18,19)$ are found to be associated with hypertension. Sleeping for less than five hours per a day (18), oral contraceptive pills (17), alcohol intake (17), waist circumference $(15,21)$ physical inactivity (21-23), eating vegetable three or fewer days per week and salt use (22), obesity (20-23), higher education $(16,21)$ and vigorous recreational activities (16) were associated with hypertension.

\section{Discussion}

Hypertension is an important public health problem in developing countries and Ethiopia is not different in this regard. Based on the available data, the present study attempted to synthesize the evidence on prevalence and associated factors for hypertension. Even though there are some researches done in Ethiopia that provide data on hypertension, very few of these give age standardized data which allow comparability between studies and it make it difficult to conduct Meta Analysis. The individual studies show a general high prevalence of HPT. The prevalence of HPT is higher both in urban and older age groups.

In most studies, the prevalence of HPT is higher in urban areas compared with rural counter parts; this could be due to the life style, increased stress level, urbanization and due to decrease physical activity. In this study it was very difficult to conduct trends in prevalence of hypertension because the studies were undertaken at different populations and age groups.

The data in this review provide estimates of the burden of hypertension in different regions of Ethiopia. Only studies which use JNC7 criteria/antihypertensive medication were included in the review; this was made for comparison purpose. Variations in BP measurement methodology, age range and study site made it difficult for comparison of study.

Studies were included based on the extent to which the methods used were likely to give results which were representative of the population from which samples were drawn. To achieve this, studies were included only if the response rate had been mentioned and was at least $90 \%$ and sample size was reasonably large (400 participants).

There is an urgent need to encourage healthy lifestyles as a means of primary prevention and also to increase awareness of hypertension through public education and creating BP screening centers in different recreational and social settings like school, church, market, mosque and others.

\section{Strengths and Weaknesses}

In the absence of vital statistics system, epidemiological studies on non-communicable diseases, with a variety of designs and in-depth analysis of risk factors and the effects of interventions, could provide a better understanding of the situations in Ethiopia and provide information to healthcare policy-making. Only a few studies were carried out with the same age group, which created some difficulties in pooling of age specific prevalence, to pool associated factors and conduct Meta Analysis.

Although this review includes hospital-based studies which are largely non-representative of the community, it can highlight gaps on the understanding of the major noncommunicable diseases in the country. Future research priorities for the country should include better quantification of the major non-communicable diseases and locallyimportant risk factors.

\section{Conclusion and Recommendation}

The prevalence of major non-communicable diseases in Ethiopia is high, with probable underreporting, and will certainly increase in the upcoming years. Providing critical data to formulate evidence based health policy and intervention will play a tremendous role. So, future researchers shall produce evidences in different regions and shall use the same reference criteria for comparison purpose. Moreover, primary prevention tailored to provide education on modifiable life-styles addressing the health consequences of alcohol consumption, physical inactivity, and dietary pattern and to establish BP screening in primary health care context would be of immense value. On top of these, proactive thinking integrated with the primary healthcare system could be the best way to reduce the burden both in the rural and urban settings of the country. It could also enhance healthy behaviors and mitigate the rise in the incidence of major non-communicable diseases in the country. Because of the limited number of studies on HPT in Ethiopia, upcoming well-powered studies, using the standardized research design and covering more regions of the country and Meta Analysis studies are recommended.

Further investigation is important for other Chronic Non Communicable diseases such as Diabetes mellitus, cardiovascular disorders, cancer, and other diseases like chronic obstructive lung diseases.

\section{Acknowledgement}

First and for most I would like to acknowledge my colleagues Fisha Girma and Ashenafi Shumye for their valuable comments and critics and involvements in the decision making process of selecting studies.

My deepest gratitude also goes to my beloved families for their moral and financial support. 
Finally, I would like to thank my wife Wint and my sister Nigest for your day and night moral support and encouragement.

\section{References}

[1] Kearney PM, Whelton M, Reynolds K, Munter P, WheltonPK, He J: Global burden of hypertension: analysis of worldwide data. Lancet 2005, 365:217-23.

[2] W.H.O: Global status report on Noncommunicable diseases; 2014

[3] Chobanian AV, Bakris GL, Black HR, et al. Seventh report of the Joint National Committee on Prevention, Detection, Evaluation, and Treatment of High Blood Pressure. JAMA. 2003;289:2560-2572.

[4] Causes of Death 2008 [online database]. Geneva, World Health Organization

[5] Lim SS, Vos T, Flaxman AD, Danaei G, Shibuya K, AdairRohani $\mathrm{H}$ et al. A comparative risk assessment of burden of disease and injury attributable to 67 risk factors and risk factor clusters in 21 regions, 1990- 2010: a systematic analysis for the Global Burden of Disease Study 2010. Lancet. 2012; 380(9859):2224-60.

[6] W.H.O:GLOBAL HEALTH RISKS; Mortality and burden of diseaseattributable to selected major risks, 2009

[7] A global brief on hypertension. Silent killer, global public health crisis. Geneva: World Health Organization; 2013.

[8] Prevention of cardiovascular disease: guidelines for assessment and management of cardiovascular risk. Geneva: World Health Organization; 2007.

[9] W.H.O: A global brief on Hypertension; Silent killer, global public health crisis, World Health Day 2013

[10] World Health Organization and World Economic Forum. From Burden to "Best Buys": Reducing theEconomic Impact of Non-Communicable Diseases in Low- and Middle-Income Countries. Geneva, World Health Organization and World Economic Forum, 2011

[11] The Global Economic Burden of Non-communicable Diseases. World Economic Forum and the Harvard School of Public Health, 2011.

[12] Tesfaye F: Epidemiology of cardiovascular disease risk factors in Ethiopia: the rural-urban gradient. J Hum Hypertens 2007, $21(2): 28-37$
[13] Central statistical Agency (CSA) [Ethiopia]. Ethiopia demographic and Health Survey. Central Statistical Authority, Addis Ababa. 2011: 1-22

[14] Moher D, Liberati A, Tetzlaff J, et al. Preferred reporting items for systematic reviews and meta-analyses: the PRISMA Statement. PLoS Med. 2009; 6:e1000097.

[15] Feyie B, Esayas K, Kifle W. Prevalence of Hypertension and its risk factors among adults in Bedele town. Ethio J Health Sci.,2014;24:1

[16] Tesfa B, Fessahaye A. An Analysis of Survey Data on Chronic Non-Communicable Disease at Gilgel Gibe Field Research Center, South West Ethiopia. Science Journal of Public Health. Vol. 3, No. 2, 2015, pp. 281-290. doi: 10.11648/j.sjph.20150302.29

[17] Esayas K, Yadani M, Sahilu A. Prevalence of hypertension and its risk factors in southwest Ethiopia: a hospital basedcross-sectional survey. Integrated blood pres contr. 2013, 6:111-117

[18] Takele T, Henok A. Hypertension and associated factors among University students in Gonder, Ethiopia. BMC Public health 2014, 14:937 http://www.biomedcentral.com /14712458/14/937

[19] Mekoya D. Pattern of blood pressure distribution and prevalence of hypertension and prehypertension among adults in Northern Ethiopia: disclosing the hidden burden. BMC Cardiovascular Disorders 2014, 14:33 http://www.biomedcentral.com /1471-2261/14/33

[20] Assefa B, Haftu B, Alemayehu B. Prevalence and associated factors of Hypertension among adult population, in Mekelle city, Northern Ethiopia. ijipsr, 2(3),2014,653-668

[21] Tesfaye F, Byass P, Wall S: Population based prevalence of high blood pressure among adults in Addis Ababa: uncovering a silent epidemic. BMC CardiovascDisord 2009, 9:39.

[22] HeleloTP, Gelaw YA, Adane AA (2014) Prevalence and Associated Factors of Hypertension among Adults in Durame Town, Southern Ethiopia. PLoS ONE 9(11): e112790. doi:10.1371/journal.pone.0112790

[23] Awoke A, Awoke T, Alemu S, Megabiaw B. Prevalence, and associated factors of hypertension among adults in Gondar, Northwest Ethiopia. BMC Cardiovascular Disorders 2012; 12 (1):1 6.Available at: http://www.biomedcentral.com/14712261/12/113 